\title{
Urban logistics profile - Yogyakarta city, Indonesia
}

\author{
Anna Maria Sri Asih, Bertha Maya Sopha, and Siti Mardiyah \\ Industrial Engineering Programme, Department of Mechanical and Industrial Engineering
}

\begin{abstract}
In recent years, more rural areas are becoming urban areas accompanied by escalation of logistics activities. Unlike passenger transport, the planning, policy and control of freight transport in developing countries have not been integrated into a reliable and efficient logistics system. Therefore, generating city logistics profile is necessary in order to support the planning of urban logistics system. This study aims to establish a logistics profile of Yogyakarta city, Indonesia, by dividing urban zones into several homogeneous groups, judging from several aspects, including city area features, product characteristics and agents/delivery profile. Logistics profile variables were calculated based on administrative boundaries, resulting in 45 areas to be investigated. Profiles were matched in groups of homogeneous stores (A), large commercial stores (C) and residential areas with local trade (D), with one overlapping profile, i.e. profile A and profile $\mathrm{D}$, in some locations in the middle of the city.
\end{abstract}

\section{Introduction}

In recent years, there has been a shift of population concentration in rural areas to the city, especially in developing countries. This phenomenon has caused escalation of logistics activities to meet the needs of industrial sector as well as the household sector. This may allow for negative impacts if those activities are not handled properly, i.e. congestion, noise, decreased air quality due to vehicle emissions (Quak, 2008). In contrast to passenger transport, generally the planning, policy and control of freight transport have not been yet integrated in a reliable and efficient logistics system. Therefore, in order to support the planning of urban logistics system, logistics profile maps is necessary to be developed.

Logistics profile is a concept introduced by Macario et al. (2008). This concept is to divide urban zones in several homogeneous groups, judged from several criteria including city area features, product characteristics, and agents / deliveries profiles. These three criteria are then called logistic profile elements. This concept was used to establish logistical profiles in Lisbon (Alho \& de Abreu e Silva, 2014). The result of this research is the formation of four profiles and from these results, four types of logistics regulations can be made. The enactment of logistics regulations may have different effects in regions with different characteristics (Anderson et al., 2010). By using a logistics profile, logistics problems can be anticipated by adjusting logistics regulations based on the profiles developed. One example of its application is on TURBLOG (Transferability of urban logistics) project (2011). In this project, five logistic profiles were created which were then matched to the conditions of several different cities. The cities in the TURBLOG project are Paris (France), Utrecht (Netherlands), Belo Horizonte (Brazil), Santiago de Chile (Chile), Tokyo (Japan), Beijing (China), New York (USA), and Mumbai (India).

Results of TURBLOG project showed that an area in Mumbai, India, was categorized in profiles requiring special conditions on the distribution process, e.g. for perishable or frozen foods and solid distribution path conditions at certain hours. Mumbah Dabbawalas Operation System implemented an effective logistics model under these conditions, i.e. door-to-door delivery using public transport and non-pollutant vehicles or bicycles. In addition to Mumbai, in Belo Horizonte, Brazil, the Business-to-Consumer concept was used to deliver goods from producers directly to consumers. Other areas with different profiles, for example areas with many retail stores such as the Monoprix's supermarket in Paris, the policy of using the Monoprix rail train was effectively used. Other policies under different profile conditions may also be applied such as vehicle restrictions, time window applicability, and logistics routes as applied in Utrecht for the majority of logistics profiles adjacent to residential areas.

Logistics profile created in Alho and de Abreu e Silva (2014) used combination of logistic profile elements similar to those used in the TURBLOG project but with some adjustments to the condition of the research object i.e. city of Lisbon, Portugal. An example of adjustment is that the restriction variable in the city area features elements is ignored because this variable did not have too much effect on the logistics profile. In addition to restriction variables, logistics accessibility variables are

${ }^{*}$ Corresponding author: amsriasih@ugm.ac.id 
also adjusted due to unavailability of data on the level of congestion so that data is replaced with available loading/unloading bay data in Lisbon city. In addition to the adjustment of several variables, another thing that distinguished this research (Alho and de Abreu e Silva, 2014) with the TURBLOG project is the use of quantitative methods to determine the value of the frequency of delivery variable, which is one of the agents/deliveries profile elements. Unlike other logistic profile variables, this variable requires another approach for the calculation process, which can be done by computing the freight trip generation or the number of trips/trips resulting from the logistics activities. The calculation of freight trip generation can be carried out in different ways, both qualitative and quantitative and using different data according to city conditions and availability of data (Alho and de Abreu e Silva, 2014).

The combination of elements in the logistics profile can also be tailored to the purpose of making it more flexible in combination with other urban logistics cases. This paper aims to use this concept to built logistics profile in Yogyakarta city, Indonesia. In the Special Region of Yogyakarta, the development of the trade sector in 2009-2014 is generally experiencing positive developments. Trading business in DIY is dominated by micro and small entrepreneurs and contributed by availability of trading facilities such as modern stores and traditional markets. The number of modern stores until 2014 amounted to $15 \%$ more than traditional markets. Increasing the number of modern stores becomes a rising concern in managing logistics problems, e.g. congestions and negative effect on environment and social life. Thus, logistics policy is required in order to anticipate them. This policy includes many considerations based on characteristics owned by each area in the city, which can be seen if logistics profile map is created.

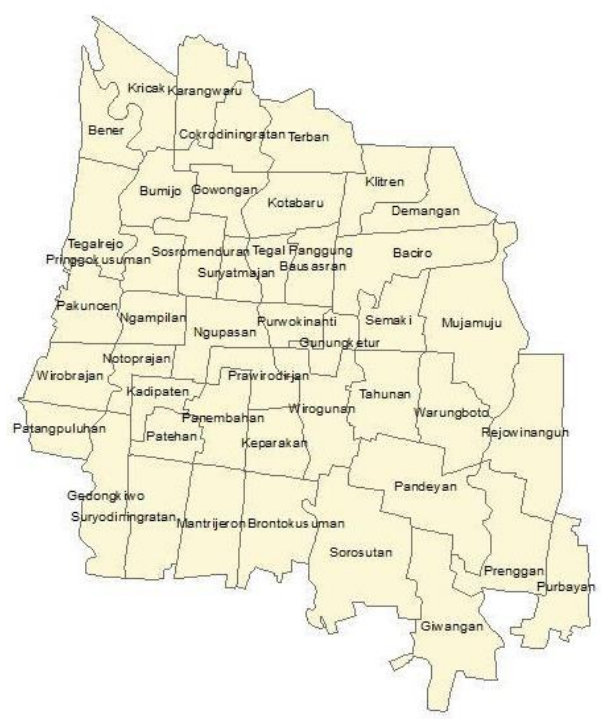

Figure 1. Yogyakarta city's administrative boundaries

\section{Methodology}

Yogyakarta city, as a studied case, has total area of 32.5 $\mathrm{km}^{2}(1.02 \%$ of the total area of Yogyakarta Special Province). Administratively, the city of Yogyakarta consists of 45 sub-districts. This city is divided into fishnet based on those sub-districts boundary (see Figure 1). Information used as the object of this study is data of stores registered in the city of Yogyakarta, with the total number of 4190 stores. Figure 2 is the result of the entire store map, shown alongside with the boundaries.

This paper combine logistic profile concept from Macario et al. (2008) and TURBLOG concept. Table 1 shows the elements of logistic profile from Macario et al. (2008), adjusted to the conditions of Yogyakarta city. Implementation of this concept to logistics practices, i.e. how is the logistics profile for specific area or land uses, was combined with logistics profile developed by TURBLOG (2011), which is summarized as follows:

- Groups of homogeneous stores, which sellthe same type of product or services

- Hotels, restaurants

- City Business District

- Large shopping centers

- Residential areas

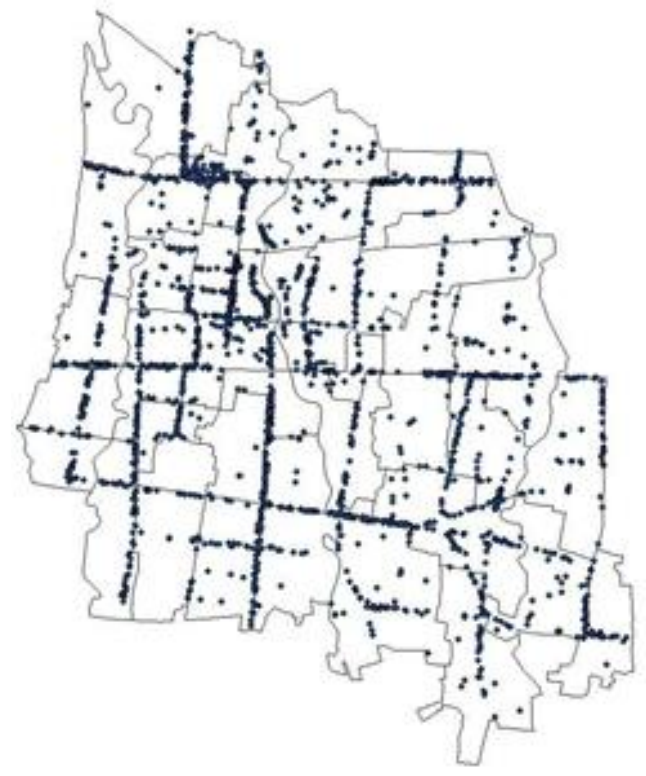

Figure 2. Distribution of stores'location within Yogyakarta city, represented by black dots

In the process of developing Yogyakarta's logistics profile, B profile is not used because of many constraints in collecting data of this profile. Adjusted logistics profile (TURBLOG, 2011) to Yogyakarta city is shown in Table 2 
Table 1. Elements of Logistics Profile (Macario et al. 2008) - adjusted for Yogyakarta city

\begin{tabular}{|c|c|c|c|c|c|}
\hline \multirow{2}{*}{\multicolumn{2}{|c|}{$\begin{array}{l}\text { Name of variable } \\
\text { City area features }\end{array}$}} & \multirow[t]{2}{*}{ Type of variable } & \multicolumn{3}{|c|}{ Classification } \\
\hline & & & & & \\
\hline \multirow[t]{3}{*}{1.1} & Commercial density & continuous & Low & Medium & High \\
\hline & & & $<20 \%$ & $30 \%-70 \%$ & $>70 \%$ \\
\hline & & & Commercial face to residenci & service / industries & \\
\hline \multirow[t]{2}{*}{1.2} & Homogeneity & continuous & Low & Medium & High \\
\hline & & & $\begin{array}{l}\text { Several types of services and } \\
\text { products }\end{array}$ & $\begin{array}{l}\text { Mix of residential areas with offices } \\
\text { and commercial stores }\end{array}$ & $\begin{array}{l}\text { Cluster of one type of services or } \\
\text { similar products }\end{array}$ \\
\hline \multicolumn{6}{|c|}{ Product characteristics } \\
\hline 2.1 & Easiness of Handling & ordinal/categorical & difficult & reasonable & Easy \\
\hline 2.1.1 & Size & ordinal/categorical & Large (wheelbarrow, crane) & Medium ( $>1$ person to carry one unit) & Small ( $>1$ unit per person to carry) \\
\hline 2.1.2 & Weights & ordinal/categorical & Heavy (wheelbarrow, crane) & Medium (>1 person to carry one unit) & Light ( $>1$ unit per person to carry) \\
\hline 2.2 & Special Conditions & ordinal/categorical & $\begin{array}{l}\text { Special needs (e.g. valuable } \\
\text { products and frozen } \\
\text { products) }\end{array}$ & $\begin{array}{l}\text { Might have special needs (e.g. open } \\
\text { packages, if food handled ambient } \\
\text { temperature and chilled) }\end{array}$ & No special needs \\
\hline \multicolumn{6}{|c|}{ Agents/deliveries profile } \\
\hline 3.1 & $\begin{array}{l}\text { Frequency of } \\
\text { deliveries }\end{array}$ & continuous & Low (< once a week) & Medium (several days per week) & High (daily) \\
\hline
\end{tabular}

Table 2. Logistics Profile (TURBLOG, 2011) - adjusted for Yogyakarta city

\begin{tabular}{|c|c|c|c|c|c|}
\hline \multirow{2}{*}{ Elements/variables } & \multicolumn{5}{|c|}{ Profile } \\
\hline & A & B & $\mathrm{C}$ & D & $\mathrm{E}$ \\
\hline Commercial density & High & - & High & High & Low/medium \\
\hline Homogeinity & High & - & Low & Low & Low/medium \\
\hline Easiness of handling & - & - & Easy & - & - \\
\hline Special condition & - & Special needs & No special needs & - & - \\
\hline Frequency of deliveries & - & High & High & Medium/high & Low/medium \\
\hline
\end{tabular}

In order to get quantitative interpretation of logistics profile in Table 2, variables defined should be measured and calculated. Values obtained from above calculations were used to evaluate the fishnets that meet the values. Detail of calculations refers to Alho and de Abreu e Silva (2015) and it is explained briefly as follows:

1. Commercial density was calculated by dividing the number of stores in each fishnet by the area of the related fishnet.

2. Homogeneity calculation was based on entropy concept. The lower the number obtained is associated with increased homogeneity.

3. Easiness of handling was calculated based on two indicators, i.e. weight and volume as representation of size (see Table 1)

4. Special conditions has three attributes, i.e. fragile, perishable and refrigerated (see Table 1)

5. Frequency of deliveries was calculated using two indicators, i.e. sum of establishment deliveries and average of establishment of deliveries.

\section{Results and Discussion}

Results summary of continuous variables and ordinal/categorical variables are shown in Table 3 and Table 4. Values of continuous variables are presented by Min, Max, Average and Standard Deviation, whereas ordinal/categorical variables are presented by proportion of each variable in each industry category (Table 5).

Quantitative interpretation of logistics profile obtained from calculations above is shown in Table 6 . This table was then used to determine which fishnet that meet the specification for each profile mentioned in Section 2 (see Table 2). Maps of the results are shown in Figure 3. In Table 2, high is defined as a half standard deviation above average value and low is a half standard deviation below average value

Table 3. Summary of continuous variables

\begin{tabular}{lcccc}
\hline \multicolumn{1}{c}{ Name of variable } & Min & Max & Average & Standard Deviation \\
\hline Commercial density & 6 & 542 & 155 & 123 \\
Sum of establishments of weekly deliveries & 6 & 1400 & 384 & 309 \\
Average of establishments of weekly deliveries & 1 & 12 & 4 & 2 \\
Homogeneity & 0.24 & 0.92 & 0.78 & 0.12 \\
\hline
\end{tabular}

Table 4. Summary of ordinal/categorical variables

\begin{tabular}{|c|c|c|c|c|c|c|c|c|c|c|}
\hline \multirow[t]{2}{*}{ Name of variable } & \multicolumn{10}{|c|}{ distribution } \\
\hline & 1 & 2 & 3 & 4 & 5 & 6 & 7 & 8 & 9 & 10 \\
\hline Industry category & $24 \%$ & $17 \%$ & $6 \%$ & $1 \%$ & $5 \%$ & $6 \%$ & $2 \%$ & $10 \%$ & $11 \%$ & $18 \%$ \\
\hline Number of special item attributes & $48 \%$ & $52 \%$ & $0 \%$ & - & - & - & - & - & - & - \\
\hline Item's weight & $9 \%$ & $76 \%$ & $15 \%$ & - & - & - & - & - & - & - \\
\hline Item's volume & $9 \%$ & $76 \%$ & $15 \%$ & - & - & - & - & - & - & - \\
\hline
\end{tabular}


Table 5. List of industry categories

\begin{tabular}{ll}
\hline No & Industry category \\
\hline 1 & Food/beverage \\
2 & Textile/clothing/shoes \\
3 & Paper/printing \\
4 & Petro-chemical \\
5 & Non-metallic \\
6 & Primary metal \\
7 & Machinery \\
8 & Electronics \\
9 & Transportation equipment \\
10 & others \\
\hline
\end{tabular}

Table 6. Summary of quantitative interpretation of logistics profiles

\begin{tabular}{|c|c|c|c|c|c|}
\hline \multirow[t]{2}{*}{ Variable name } & \multicolumn{5}{|c|}{ Profile } \\
\hline & A & B & $\mathrm{C}$ & D & $\mathbf{E}$ \\
\hline Commercial density & $\geq 217$ & - & $\geq 217$ & $\geq 217$ & $\leq 155$ \\
\hline Homogeneity & $\leq 0.72$ & - & $\geq 0.84$ & $\geq 0.84$ & $\geq 0.78$ \\
\hline Easiness of handling (weight) & - & - & 1 & - & - \\
\hline Easiness of handling (volume) & - & - & 1 & - & - \\
\hline Special conditions & - & - & 1 & - & - \\
\hline Frequency of deliveries (sum of establishment deliveries) & - & - & $\geq 539$ & $\geq 384$ & $\leq 384$ \\
\hline Frequency of deliveries (sum of establishment deliveries) & - & - & $\geq 5$ & $\geq 4$ & $\leq 4$ \\
\hline
\end{tabular}

Figure 3 shows that profile A laid in three areas, one at the north, one area in the middle of the city and one in the southeast part of the city. Bausasran sub-district, which is located at the north is dominated by shops selling food and basic necessities (56\%). Other area, Sosromenduran in the middle of the city, has 50\% stores selling clothing and textiles with the rest consists of various types of stores, including flower shops alongside a street inside this sub-district. Prenggan, which is located at the southeast is dominated by numerous craft shops, especially from silver. Silver handicraft industry in this area is dominated by small enterprises.

Profile C or business center / CBD (courier, small deliveries, B2C), does not have members, or in other words there is no district in the city that matched the characteristics of the profile elements of logistics in accordance with the profile of $\mathrm{C}$. This is due to the high requirements to be able to fit profile $\mathrm{C}$, such as high frequency of delivery, while it is only medium/high for profile D.

Profile D, which is large commercial (retail, shopping centers, distribution warehouse), is found mostly in the middle of the city as there are lots of big stores alongside the streets. In addition of the other three profiles, there are three sub-district, i.e. Sosromenduran, Suryatmajan and Ngupasan (red color), which represent overlapping of profile A and D. These areas are actually corresponds to Malioboro street and its surroundings, which is well known as major shopping street in Yogyakarta with some large shopping malls in it. Therefore, delivery of goods is very frequent in this area. The last profile, E, is residential areas with local trade which is spread in several locations in the north, west, south and middle of the city. These areas are characterized with medium population area. The findings shows that the result of logistics profile is indeed influenced by combination of variables forming the logistic profile and conditions of the city. Hence, different regional area with different characteristics will have combination of different logistics profile elements and thus different map of logistics profile.

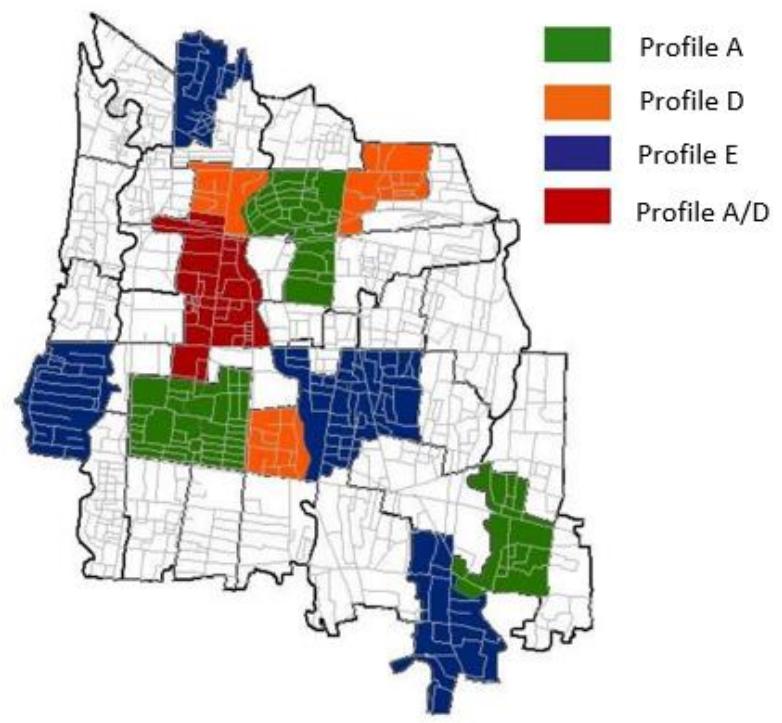

Figure 3. Logistics profile map of Yogyakarta city

\section{Conclusion}

Logistics profile concept has been adapted to the conditions of Yogyakarta city, producing three profiles matched, i.e. profile A (groups of homogeneous stores), profile D (large commercial stores), and E (residential areas with local trade) with one additional overlapping profile (profile A and profile D). Profile B was not formed as many constraints in data collection and unavailability of data on urgency and planned delivery. On the other hand, profile $\mathrm{C}$ was not formed because none of the areas can match the requirements of this profile. The profiles 
obtained is expected to be used in the next stage in formulating policies related to the logistics management in this city.

The authors wish to thank Higher Education Directorate (DIKTI) Indonesia for their financial supports under the research grant of Master Pengembangan dan Percepatan Pertumbuhan Ekonomi Indonesia (MP3EI) 2017.

\section{References}

1. Alho, A.R. \& de Abreu e Silva, J. Utilizing urban form characteristics in urban logistics analysis: a case study in Lisbon, Portugal. Journal of Transport Geography, 42, 57-71. (2014).

2. Alho, A.R. \& de Abreu e Silva, J. Modeling retail establishment's freight trip generation: a comparison of methodologies to predict total weekly deliveries. Transportation. doi:10.1007/s11116-015-9670-6. (2015).

3. Anderson, S., Allen, J., Browne, M. Urban logistics how can it meet policy makers sustainability objectives. Journal of Transport Geography. 13(1). 71-81. (2005).

4. Macario, R., Galelo, A., Martins, P.M. Business models in urban logistics. Ingeniería Desarrollo. 7796. (2008).

5. Quak, H.J. Sustainability of urban freight transport retail distribution and local regulations in cities (Ph.D. thesis, Erasmus University Rotterdam, the Netherlands). (2008).

6. TURBLOG. Transferability of urban logistics concepts and practices from a worldwide perspective. Deliverable 2: Business Concepts and Models for Urban Logistics. TIS.pt, Portugal. (2011). 